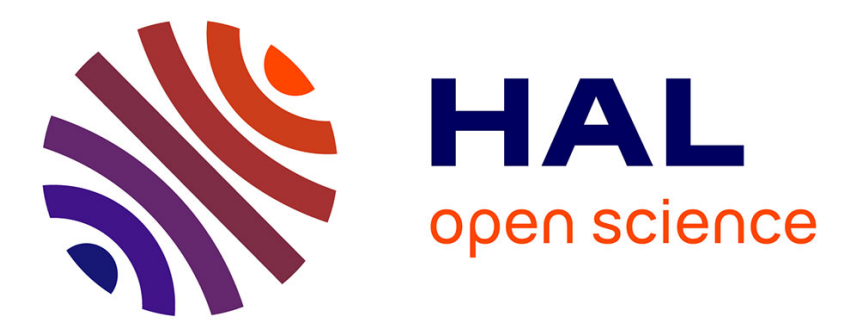

\title{
A Passivity-Based Controller Under low sampling for speed control of PMSM
}

\author{
Mohamed Khanchoul, Mickaël Hilairet, Dorothée Normand-Cyrot
}

\section{To cite this version:}

Mohamed Khanchoul, Mickaël Hilairet, Dorothée Normand-Cyrot. A Passivity-Based Controller Under low sampling for speed control of PMSM. Control Engineering Practice, 2014, 26, pp.20-27. 10.1016/j.conengprac.2013.12.013 . hal-00980120

\section{HAL Id: hal-00980120}

https://hal-centralesupelec.archives-ouvertes.fr/hal-00980120

Submitted on 17 Jul 2014

HAL is a multi-disciplinary open access archive for the deposit and dissemination of scientific research documents, whether they are published or not. The documents may come from teaching and research institutions in France or abroad, or from public or private research centers.
L'archive ouverte pluridisciplinaire HAL, est destinée au dépôt et à la diffusion de documents scientifiques de niveau recherche, publiés ou non, émanant des établissements d'enseignement et de recherche français ou étrangers, des laboratoires publics ou privés. 


\title{
A passivity-based controller under low sampling for speed control of PMSM
}

\author{
M. Khanchoul ${ }^{\mathrm{a}}$, M. Hilairet ${ }^{\mathrm{b}, *}$, D. Normand-Cyrot ${ }^{\mathrm{c}}$ \\ a LGEP/SPEE Labs, CNRS UMR 8507, SUPELEC, Univ Pierre et Marie Curie-P6, Univ Paris Sud-P11, 91192 Gif sur Yvette, France \\ ${ }^{\mathrm{b}}$ Franche-Comté Electronique Mécanique Thermique et Optique - Sciences et Technologies (FEMTO-ST), Université de Franche-Comté, Belfort, France \\ ' L2S, CNRS UMR 8506, SUPELEC, Université Paris-Sud 11, 91192 Gif sur Yvette, France
}

\section{A R T I C L E I N F O}

\section{Article history:}

Received 30 April 2013

Accepted 24 December 2013

Available online 1 February 2014

Keywords:

Permanent magnet synchronous motor (PMSM)

Sampled-data control

Port-controlled Hamiltonian systems

IDA-PBC techniques

Experimental validation

\begin{abstract}
A B S T R A C T
Controller performances are strongly limited by the switching frequency of the converter and the computational capacity of the target board. Therefore, in such a context the design of controllers that provide good performances under possible large sampling period length is necessary. To tackle these limitations, a digital design is described for speed control of permanent magnet synchronous machines. It is based on the interconnection and the damping assignment passivity-based control (IDA-PBC) techniques extensions to the sampled-data context.
\end{abstract}

(c) 2014 Elsevier Ltd. All rights reserved.

\section{Introduction}

Nowadays, PMSM is used in many fields. This gain in popularity is due to its attractive features such as high power/mass ratio, rapid dynamic response due to high torque-to-inertia ratio while compactness and easy modeling and control (Bose, 2002; Giri, 2013). In addition, the presence of the magnet in the rotor reduces the Joule losses due to the absence of winding excitation in the rotor and this makes PMSM highly efficient.

Several position and velocity controllers for PMSM have been reported in the control literature, such as field oriented control (FOC) or direct torque control (DTC) (Buja \& Kazmierkowski, 2004; Giri, 2013; Wang, Zhu, \& Guo, 2007), to quote the most popular. These controllers are designed using a cascade of two controllers: an outer loop for the speed control and an inner loop for the currents control. The different strategies make use of PI or IP controllers, adaptive PI controller (Li \& Liu, 2009), sliding mode controller (Baik, Kim, \& Young, 2002; Laghrouche, Plestan, \& Glumineau, 2004), predictive controller (Mariethoz, Domahidi, \& Morari, 2009), backstepping controller (Zhou \& Wang, 2002), Lyapunov-based controller (Hernandez-Guzman \& Silva-Ortigoza, 2011) or passivity-based controller (Akrad, Diallo, \& Ortega, 2007; Ortega \& Garcia-Canseco, 2004; Petrovic, Ortega, \& Stankovic, 2001). The recently developed energy-shaping technique

\footnotetext{
* Corresponding author.

E-mail addresses: mohamed.khanchoul@lgep.supelec.fr (M. Khanchoul), mickael.hilairet@univ-fcomte.fr (M. Hilairet),

cyrot@Iss.supelec.fr (D. Normand-Cyrot).
}

(Ortega \& Garcia-Canseco, 2004; Ortega, van der Schaft, Castanos, \& Astolfi, 2008) or interconnection and damping assignment passivitybased control (IDA-PBC) achieves the global stabilization of PMSMs (Akrad et al., 2007). In fact, integral actions are added in order to improve robustness. A technique that preserves the Hamiltonian form and closed-loop stability with integral action on the passive outputs is applied in Donaire and Junco (2009) and Donaire, Perez, and Teo (2012) to PMSM speed control.

Nevertheless, the design is generally made in continuous time while implementation through computers results in degradations due to input discretization induced by the converter and controller sampling (Monaco, Normand-Cyrot, \& Tiefensee, 2008). The reduced performances visible in oscillations or instability are mainly due to (i) the maximum allowed switching frequency of the converters for high power systems in order to limit the switching losses (in practical applications such as electrical vehicles, the switching losses limitation is mandatory to maintain the autonomy of the vehicle) and (ii) the maximum allowed sampling frequency of the processor in order to reduce the cost of the system.

Digital controllers for asynchronous machines providing good performances under large switching and large sampling periods are investigated in Delemontey, Iung, Jacquot, de Fornel, and Bavard (1995) and Gautier, Thomas, Poullain, Monaco, and Normand-Cyrot (2000) for high power traction drive. Also digital controllers for synchronous machine are developed in Georgiou, Chelouah, Monaco, and Normand-Cyrot (1992), Madani, Bonnassieux, Monaco, and Normand-Cyrot (1997), and Chelouah, Monaco, and Normand-Cyrot (1997). 
In this paper, the work initiated in Chelouah et al. (1997) and Georgiou et al. (1992) is pursued in the context of an IDA-PBC strategy. A sampled-data solution is proposed to control the currents of a permanent synchronous motor with a regular field oriented control strategy. This paper presents a digital passivity based control procedure recently developed in Monaco, Normand-Cyrot, and Tiefensee (2011), Tiefensee, Hilairet, Normand-Cyrot, and Béthoux (2010), and Tiefensee, Monaco, and Normand-Cyrot (2009). A digital controller preserving passivity is proposed. In practice, such an approach extends the usual zero order holding $(\mathrm{ZOH})$ device used for implementing control with well-known degradations.

The paper is organized as follows. In Section 2, the continuoustime IDA-PBC method is recalled and applied to the currents control of a PMSM. In Section 3, the digital strategy is recalled and a digital passivity based controller is described for both strategies. Simulations and experimental results are presented in Section 4 where the performance gain according to the sampling frequency is discussed. The computational cost of the proposed digital controller is also compared with the usual implementation through emulation ( $\mathrm{ZOH}$ device).

\section{The continuous-time IDA-PBC approach}

In the continuous time domain, the fundamental idea behind IDA-PBC is to transform the internal structure into a desired stable one with a desired equilibrium. Interconnection and damping assignment passivity-based control is thus a control technique that shapes both the closed loop structure by assigning a desired port-controlled Hamiltonian (PCH) one and improves stabilization through damping injection.

\subsection{Some recalls about the IDA-PBC strategy}

The procedure starts with the system's description in the port controlled Hamiltonian structure:

$$
\begin{aligned}
& \dot{x}(t)=[\mathcal{J}(x(t))-\mathcal{R}(x(t))] \nabla H(x(t))+g(x(t)) u(t)+\zeta(t) \\
& y(t)=g^{T} \nabla H(x(t))
\end{aligned}
$$

where $x(t) \in \mathbb{R}^{n}$ is the state vector, $u(t) \in \mathbb{R}^{m}$ is the control vector, $y(t) \in \mathbb{R}^{m}$ is the output vector with $m<n, \zeta(t)$ is a perturbation, $H(x): \mathbb{R}^{n} \longrightarrow \mathbb{R}$ is the total stored energy, $\nabla H(x)$ is the gradient of the energy function, $\mathcal{J}(x(t))=-\mathcal{J}(x(t))^{T}, \mathcal{R}(x(t))=\mathcal{R}^{T}(x(t)) \geq 0$ are the interconnection and damping matrices respectively. $\mathrm{PCH}$ models have been selected as natural candidates to describe many physical systems.

Proposition 1 (Ortega and Garcia-Canseco, 2004). Consider the nonlinear system

$\dot{x}(t)=f(x(t))+g(x(t)) u(t)$

Assume the existence of matrices $g^{\perp}(x(t)), \mathcal{J}_{d}(x(t))=-\mathcal{J}_{d}^{T}(x(t))$, $\mathcal{R}_{d}(x(t))=\mathcal{R}_{d}^{T}(x(t)) \geq 0$ and a function $H_{d}(x): \mathbb{R}^{n} \longrightarrow \mathbb{R}$ that verifies the partial differential equation (PDE)

$g^{\perp}(x) f(x)=g^{\perp}(x)\left[\mathcal{J}_{d}(x(t))-\mathcal{R}_{d}(x(t))\right] \nabla H_{d}(x(t))$

where $g^{\perp}(x(t))$ is a full-rank left annihilator of $g(x(t))$, that is, $g^{\perp}\left(x(t) g(x(t))=0\right.$, and $H_{d}(x(t))$ is such that

$x^{*}=\operatorname{argmin}\left(H_{d}(x(t))\right)$

with $x^{*} \in \mathbb{R}^{n}$ being the (locally) equilibrium point to be stabilized. Then, the closed-loop system (2) with the control $u$ defined as

$u(t)=\left[g^{T}(x(t)) g(x(t))\right]^{-1} g^{T}(x(t))$

$$
\times\left\{\left[\mathcal{J}_{d}(x(t))-\mathcal{R}_{d}(x(t))\right] \nabla H_{d}(x(t))-f(x(t))\right\}
$$

takes the $\mathrm{PCH}$ form

$\dot{x}(t)=\left[\mathcal{J}_{d}(x(t))-\mathcal{R}_{d}(x(t))\right] \nabla H_{d}(x(t))$

with $x^{*}$ being a (locally) stable equilibrium. It will be asymptotically stable if, in addition, $x^{*}$ is an isolated minimum of $H_{d}(x(t))$ and the largest invariant set under the closed-loop dynamics (6) contained in

$\left\{x \in \mathfrak{R}^{n} \mid\left[\nabla H_{d}(x(t))\right]^{T} \mathcal{R}_{d}(x(t)) \nabla H_{d}(x(t))=0\right\}$

equals $x^{*}$. An estimate of its domain of attraction is given by the largest bounded level set $\left\{x \in \mathfrak{R}^{n} \mid H_{d}(x(t)) \leq c\right\}$.

Proof. Setting up the right hand side of (2) equal to the right hand side of (6), we get the matching equation

$f(x(t))+g(x(t)) u(t)=\left[\mathcal{J}_{d}(x(t))-\mathcal{R}_{d}(x(t))\right] \nabla H_{d}(x(t))$

Multiplying on the left by $g^{\perp}(x(t))$, we obtain the PDE (3). The expression of the control is obtained by multiplying on the left by the pseudo-inverse of $g(x(t))$. Stability of $x^{*}$ is established noting that, along the trajectories of (6), we have

$\dot{H}_{d}(x(t))=-\left[\nabla H_{d}(x(t))\right]^{T} \mathcal{R}_{d}(x(t)) \nabla H_{d}(x(t)) \leq 0$

Hence, $H_{d}(x(t))$ qualifies as a Lyapunov function. Asymptotic stability follows immediately invoking La Salle's invariance principle and the condition (7). Finally, to ensure the solutions remain bounded, we give the estimate of the domain of attraction as the largest bounded level set of $H_{d}(x(t))$.

\subsection{Permanent magnet synchronous motor control via IDA-PBC}

The model of the synchronous machine is defined in the $(d q)$ coordinates as follows:

$L_{d} \frac{d i_{d}(t)}{d t}=-R_{s} i_{d}(t)+P \Omega(t) L_{q} i_{q}(t)+v_{d}(t)$

$L_{q} \frac{d i_{q}(t)}{d t}=-R_{s} i_{q}(t)-P \Omega(t)\left(L_{d} i_{d}(t)+\phi\right)+v_{q}(t)$

$J \frac{d \Omega(t)}{d t}=P\left(L_{d}-L_{q}\right) i_{d}(t) i_{q}(t)+P \phi i_{q}(t)-f \Omega(t)-\tau_{l}(t)$

In these equations, $P$ is the number of pole pairs, $v_{d}(t), v_{q}(t)$, $i_{d}(t), i_{q}(t)$ are the voltages and the currents in the $(d q)$ coordinate, $L_{d}$ and $L_{q}$ are the stator inductances which are equal for surface permanent-magnet machines, $R_{S}$ is the stator winding resistance, $\tau_{l}(t)$ is an unknown load torque, $f$ is the friction coefficient, $\phi$ and $J$ are the flux produced by the permanent magnets and the moment of inertia respectively and $\Omega(t)$ is the mechanical speed. The $\mathrm{PCH}$ model of the PMSM takes the form (2) with

$$
\begin{aligned}
& x(t)=\left[\begin{array}{c}
L_{d} i_{d}(t) \\
L_{q} i_{q}(t) \\
J \Omega(t)
\end{array}\right], \quad u(t)=\left[\begin{array}{l}
v_{d}(t) \\
v_{q}(t)
\end{array}\right] \\
& g(x(t))=g=\left[\begin{array}{ll}
1 & 0 \\
0 & 1 \\
0 & 0
\end{array}\right], \quad \zeta(t)=\left[\begin{array}{c}
0 \\
0 \\
-\tau_{l}(t)
\end{array}\right] \\
& \mathcal{J}(x(t))=\left[\begin{array}{ccc}
0 & 0 & P L_{q} i_{q}(t) \\
0 & 0 & -P\left(L_{d} i_{d}(t)+\phi\right) \\
-P L_{q} i_{q}(t) & P\left(L_{d} i_{d}(t)+\phi\right) & 0
\end{array}\right] \\
& \mathcal{R}(x(t))=\mathcal{R}=\left[\begin{array}{ccc}
R_{S} & 0 & 0 \\
0 & R_{S} & 0 \\
0 & 0 & f
\end{array}\right]
\end{aligned}
$$

The desired equilibrium state for synchronous machines is usually selected based on the so-called "maximum torque per ampere" principle as $\left.x^{*}=\left[0, L_{q}\left(\tau_{l}(t)+f \Omega^{*}(t)\right) / P \phi\right), J \Omega^{*}(t)\right]^{T}$. The design procedure leads to the continuous-time nonlinear 
controller (5) for buried permanent magnet motor (Akrad et al., 2007):

$u(t)=\left[\begin{array}{c}\left(R_{s}-r_{1}\right) i_{d}(t)-P L_{d} i_{q}^{*}(t) \Omega(t)+P\left(L_{d}-L_{q}\right) i_{q}(t) \Omega^{*}(t) \\ \left(R_{s}-r_{2}\right) i_{q}(t)+r_{2} i_{q}^{*}(t)+P \phi \Omega^{*}(t)\end{array}\right]$

and reduces to

$u(t)=\left[\begin{array}{c}\left(R_{s}-r_{1}\right) i_{d}(t)-P L i_{q}^{*}(t) \Omega(t) \\ \left(R_{s}-r_{2}\right) i_{q}(t)+r_{2} i_{q}^{*}(t)+P \phi \Omega^{*}(t)\end{array}\right]$

for surface-mounted permanent magnet motor $\left(L_{d}=L_{q}\right)$. $r_{1}$ and $r_{2}$ are strictly positive gains. Therefore, the closed loop plant can be written as

$\dot{\tilde{x}}(t)=\left[\mathcal{J}_{d}(x(t))-\mathcal{R}_{d}\right] \nabla H_{d}(\tilde{x}(t))$

where $\tilde{x}(t)=x(t)-x^{*}$ and

$\mathcal{J}_{d}(x(t))-\mathcal{R}_{d}=\left[\begin{array}{ccc}-r_{1} & P L_{d} \Omega(t) & -\left(L_{d}-L_{q}\right) i_{q}(t) \\ -P L_{d} \Omega(t) & -r_{2} & -P \phi \\ \left(L_{d}-L_{q}\right) i_{q}(t) & P \phi & f\end{array}\right]$

The system storage function $H_{d}$ is

$H_{d}(\tilde{x})=\frac{1}{2} \tilde{x}^{T} Q \tilde{x} \quad$ with $Q=\left[\begin{array}{ccc}\frac{1}{L_{d}} & 0 & 0 \\ 0 & \frac{1}{L_{q}} & 0 \\ 0 & 0 & \frac{P}{J}\end{array}\right]$

where the minimum is reached at the point of equilibrium $x^{*}$.

Finally, a load torque estimator based on a digital linear controller gives an estimation of the load as shown in Fig. 1 to compute the desired $q$-axis current $i_{q}^{*}(t)$ (Khanchoul \& Hilairet, 2011).

Remark 1. In practice, tuning the gains $r_{1}$ and $r_{2}$ of nonlinear controller is not as easy as for linear systems. Here, if the measured speed is nearly equal to the desired speed, the controller compensates the back-emf of the machine and the transfer functions of the closed-loop currents $d$ and $q$ can be represented by first order functions, i.e. $H(p)=1 /(1+T p)$ with $T=L_{d} / r_{1}$ or $L_{q} / r_{2}$. Thus the response time $t_{r}$ at $95 \%$ for a first order system is equal to $3 T$. Therefore, the $d$ - and $q$-axis closed-loop response times $t_{r d}$ and $t_{r q}$ are respectively equal to $t_{r d}=3 L_{d} / r_{1}$ or $t_{r q}=3 L q / r_{2}$ and tune easily.

\section{Sampled-data IDA-PBC design}

To set the IDA-PBC problem in a purely discrete-time context is not an easy task. In Stramigioli, Secchi, der Schaft, and Fantuzzi (2005), the preservation of passivity of the interconnection of a continuous-time system with a discrete-time Port Control Hamiltonian system is studied. In Monaco, Normand-Cyrot, and Tiefensee (2009), it is shown that the Hamiltonian conservation can be verified under sampling with respect to a suitably defined output mapping. In the present context, because there exists a continuous-time IDA-PBC controller, we can apply the strategy proposed in Tiefensee, Monaco, and NormandCyrot (2010) and design a sampled-data controller matching the energy behavior of the closed loop system, which has been properly shaped by the continuous-time controller. The so-designed sampleddata controller is described by its series expansion around the continuous-time one. In practice, the first terms of the series are only computed and implemented to maintain the desired Hamiltonian structure and desired energy damping.

\subsection{The equivalent sampled-data model}

Assuming the control (11) or (12) constant over time intervals of length $\left.\left.T_{e} \in\right] 0, T^{*}\right]$ (a sufficiently small time interval), and denoting by $u_{k}$ its value over $\left[k T_{e},(k+1) T_{e}\right.$ [ and by $x_{k}$ the value of $x(t)$ at time $t=k T_{e}$ for $k \geq 0$, the sampled equivalent model is defined by the $T_{e}$-parameterized map

$x_{k} \rightarrow x_{k+1}=F^{T_{e}}\left(x_{k}, u_{k}\right)$

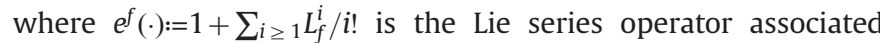
with a given vector field $f, I_{d}$ the identity operator and $L_{f}(\cdot)=$ $\sum_{i=1}^{n} f_{i}(\cdot) \partial / \partial x_{i}$ denotes the Lie derivative operator associated with a given vector field $f$ on $R^{n}$. More precisely one computes (see Monaco \& Normand-Cyrot, 1997 for details)

$$
\begin{aligned}
F^{T_{e}}\left(x_{k}, u_{k}\right)= & e^{T_{e}(f+u g)}=1+T_{e}\left(L_{f}+u L_{g}\right) \\
& +\frac{T_{e}^{2}}{2 !}\left(L_{f}^{2}+u\left(L_{f} L_{g}+L_{g} L_{f}\right)+u^{2} L_{g}^{2}\right)+\cdots+\frac{T_{e}^{p}}{p !} L_{f+u g}^{p}+\cdots
\end{aligned}
$$

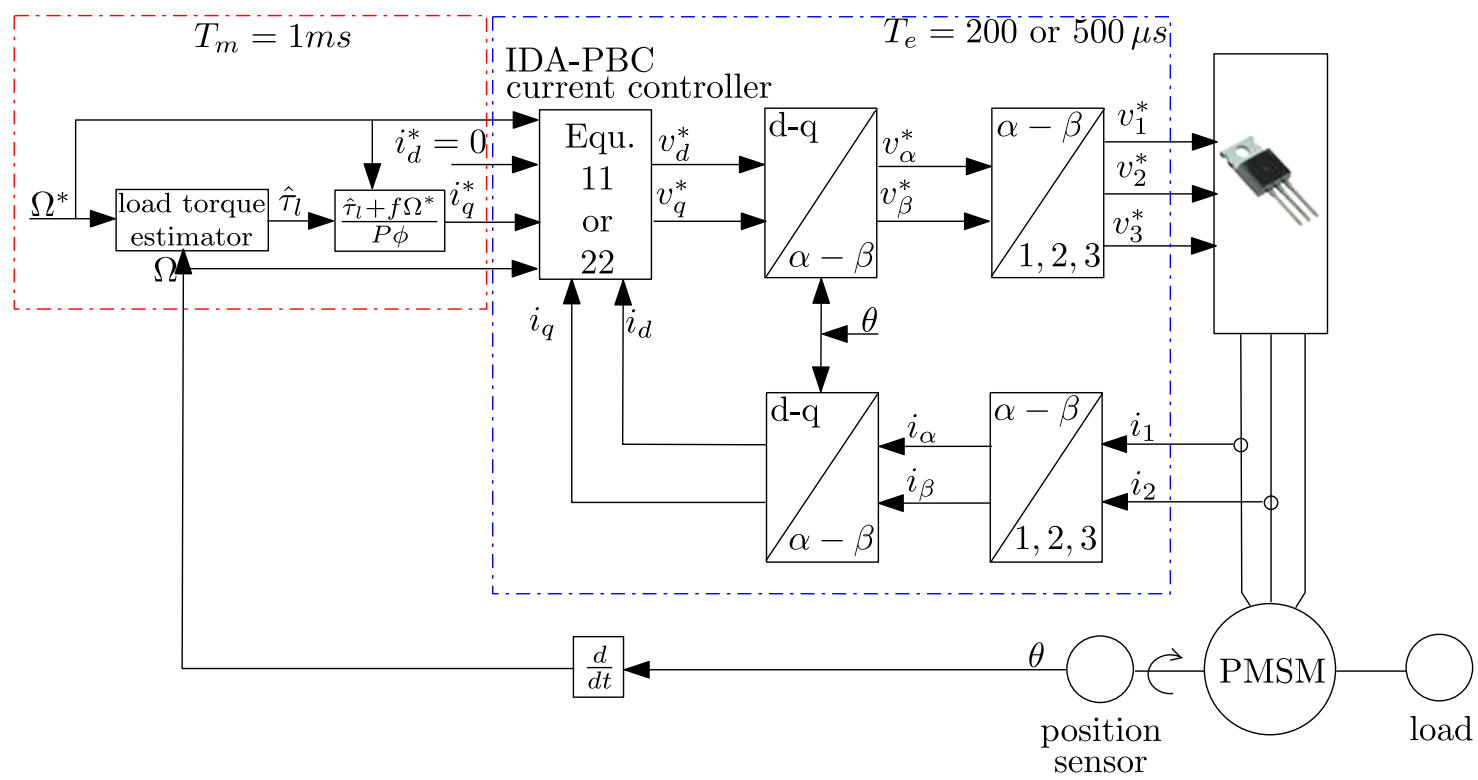

Fig. 1. IDA-PBC structure with a R-S-T digital speed controller. 
The state evolutions of $F^{T_{e}}\left(\cdot, u_{k}\right)$ coincide with that of $(1)$ at the sampling instants: $x\left(t=k T_{e}\right)=x_{k}$ for $k \geq 1$ whenever $x_{0}=x(t=0)$. To get a closed form solution requires the integrability of (1) which does not hold in general. The sampled dynamics (15) is thus described by its asymptotic series expansion in powers of $T_{e}$. Truncations in $T_{e}$ yield to approximate sampled models of order $p$ in $T_{e}$ (error in $O\left(T_{e}^{p+1}\right)$ ).

As shown in Tiefensee, Monaco, et al. (2010) the specific PCH state-space structure in (1) is lost under sampling as soon as terms of order $\geq 2$ in the equivalent sampled-data dynamics (15) are taken into account. However, it is possible to design digital controllers which match, at the sampling instants, the energetic behavior of the continuous-time target Hamiltonian function $H_{d}$.

\subsection{Energy matching under digital control}

In this paragraph, the closed-loop continuous-time state is denoted by $x_{c}$ and continuous-time control by $u_{c}$. The sampleddata state under a piecewise controller $u_{k}$ is denoted, at the time-instants $t=k T_{e}$, by $x_{k}$, its value at the instant $t=(k+1) T_{e}$ is denoted by $x_{k+1}$. The main objective is to ensure the stabilization at the equilibrium point $x^{*}$ with a good transient response under large sampling periods. For this, we look for a digital controller matching at the sampling instants the energetic behavior of the continuous-time target Hamiltonian function $H_{d}$. The design works out assuming the piecewise constant control $u_{k}$ of the form:

$u_{k}=u_{k 0}+\sum_{i \geq 1} \frac{T_{e}^{i}}{(i+1) !} u_{k i}$

and solving the following equality:

$H_{d}\left(x_{k+1}\right)-H_{d}\left(x_{k}\right)=\int_{k T_{e}}^{(k+1) T_{e}} \dot{H}_{d}\left(x_{c}(\tau)\right) d \tau$

The left hand side of (17) represents the energetic evolution of the sampled-data system and can be computed as follows (Monaco \& Normand-Cyrot, 1997):

$H_{d}\left(x_{k+1}\right)-H_{d}\left(x_{k}\right)=\frac{1}{2}\left(F^{T_{e}}\left(x_{k}, u_{k}\right)\right)^{T} Q F^{T_{e}}\left(x_{k}, u_{k}\right)-\left(x_{k}\right)^{T} Q\left(x_{k}\right)$.

The right hand side of (17) represents the energetic evolution of $x_{c}$ and can be exactly computed as follows:

$\int_{k T_{e}}^{(k+1) T_{e}} \dot{H}_{d}\left(x_{c}(\tau)\right) d \tau=H_{d}\left(\left.x_{c}\right|_{t=(k+1) T_{e}}\right)-H_{d}\left(\left.x_{c}\right|_{t=k T_{e}}\right)$

The following result can be enounced.

Proposition 2 (Tiefensee, Monaco, et al., 2010). Given (1) and assuming the existence of a continuous-time IDA-PBC as in Proposition 1 with $H_{d}$ being $C^{\infty}$-function describing the Hamiltonian target, then:

- There exists a piecewise constant controller of the form (16) ensuring matching at the sampling instants $t=k T_{e}, k \geq 0$, of the desired Hamiltonian behavior $H_{d}$.

- Asymptotic stabilization at the target equilibrium $x^{*}$ is achieved.

- The successive terms in the expansion (16) can be computed iteratively.

The sampled-data controller $u_{k}$ is described by its series expansion in $T_{e}$ around the continuous-time one $u_{k 0}=\left.u_{c}\right|_{t=k T_{e}}$ as $u_{k}=u_{k 0}+\sum_{i \geq 1}\left(T_{e} /(i+1) !\right) u_{k i}$, and each so-called "corrective" term $u_{k i}$ is computed by comparing and equating homogeneous terms in powers of $T_{e}$ in the equality (17). The computation of an exact solution being in general a difficult task due to the nonlinearities describing the continuous-time dynamics, an interesting solution can be proposed at the first order of approximation, i.e.

$u_{k}=u_{k 0}+\frac{T_{e}}{2 !} u_{k 1}$

with

$u_{k 0}=u_{c}$

$u_{k 1}=\dot{u}_{c}$

so guaranteeing Hamiltonian matching up to the second order (error in $O\left(T_{e}^{3}\right)$ ) and the Hamiltonian state space structure up to an error in $O\left(T_{e}^{2}\right)$.

Specifying this solution to the PMSM, one computes

$u_{k}=\left[\right.$ Eq. (11) or (12)] $+\frac{T_{e}}{2 !}\left[\begin{array}{l}v_{d 1} \\ v_{q 1}\end{array}\right]$

with

$$
\begin{aligned}
v_{d 1}= & \frac{R_{s}-r_{1}}{L_{d}}\left(-r_{1} i_{d}+P \Omega\left(L_{q} i_{q}-L_{d} i_{q}^{*}\right)\right. \\
& \left.+P\left(L_{d}-L_{q}\right) i_{q} \Omega^{*}\right)-\frac{P^{2}}{J} L_{d} i_{q} i_{q}^{*}\left(\left(L_{d}-L_{q}\right) i_{d}+\Phi\right) \\
& +\left(\frac{P}{L_{q}} L_{d} \Omega^{*}-P \Omega^{*}\right)\left(-r_{2}\left(i_{q}-i_{q}^{*}\right)\right. \\
& \left.-P \Phi\left(\Omega-\Omega^{*}\right)-P L_{d} i_{d} \Omega\right) \\
v_{q 1}= & \frac{R_{s}-r_{2}}{L_{q}}\left(-r_{2}\left(i_{q}-i_{q}^{*}\right)-P \phi\left(\Omega-\Omega^{*}\right)-P L_{d} i_{d} \Omega\right)
\end{aligned}
$$

for buried PMSM and in the case of a non-salient rotor $\left(L_{d}=L_{q}=L\right)$, the previous equations become

$v_{d 1}=\frac{R_{s}-r_{1}}{L}\left(-r_{1} i_{d}+P L i_{q} \Omega-P L i_{q}^{*} \Omega\right)-\frac{P^{2}}{J} L i_{q}^{*} \phi i_{q}$
$v_{q 1}=\frac{R_{s}-r_{2}}{L}\left(-r_{2}\left(i_{q}-i_{q}^{*}\right)-P L i_{d} \Omega-P \phi\left(\Omega-\Omega^{*}\right)\right)$

\section{Simulation, experimentation and discussions}

\subsection{Simulation tests}

To give an estimation of the load torque of the PMSM (Interior PMSM type, data is given in Table 2 and Fig. 2 shows the design of the machine), a RST controller (out of scope of this paper) ensures this function with a sampling time $T_{m}$ and a closed-loop response time fixed at $1 \mathrm{~ms}$ (compared to $0.17 \mathrm{~s}$ for the inner current loop). As shown in Fig. 1, the IDA-PBC controls the $(d q)$ currents with a sampling time $T_{e}$. In order to highlight the performances of the new digital controller, a comparison between the latter, emulated controller based on the continuous-time design and the continuous controller is detailed for different sampled periods.

Firstly, three control laws are compared for two configurations: (a) closed-loop dynamic of the current loop equal to $2 \mathrm{~ms}$ and a sample time $T_{e}$ equal to $1 \mathrm{~ms}$, (b) closed-loop dynamic equal to $0.2 \mathrm{~ms}$ and a sample time $T_{e}$ equal to $0.1 \mathrm{~ms}$.

Fig. 3a and b shows the step response of current $i_{q}$ controlled at zero speed by the continuous IDA-PBC, the emulated IDA-PBC (implementation of the continuous IDA-PBC with a zero-order holder, Eq. (11)), and the sampled IDA-PBC (Eq. (22)). $i_{q c}, i_{q e}$ and $i_{q k}$ represent the currents controlled by the continuous IDA-PBC, the emulated IDA-PBC and the sampled IDA-PBC respectively. The simulation shows that the current $i_{q e}$ does not reproduce the trajectory of the current $i_{q c}$ with the adopted tuning. Moreover, the latter is under-damping compared with $i_{q k}$ in configuration b (see Fig. 3b). Fig. 3c shows that the sampled-data controller reproduces 
exactly the continuous IDA-PBC current with an increment of the expansion order.

Secondly, the current controller design supposes that the converters are loss-less (no perturbation) and all the parameters are well-known. So in practice, a low integrator action with an anti-windup system needs to be added to the passivity controller in order to ensure zero error at steady state and to counteract the perturbations and parameters variation (Donaire \& Junco, 2009). The implemented controller is now

$$
\begin{gathered}
u=[\text { Eq. (22) }]+\left[\begin{array}{c}
v_{i d} \\
v_{i q}
\end{array}\right] \text { with }\left[\begin{array}{c}
\dot{v}_{i d} \\
\dot{v}_{i q}
\end{array}\right]=-K_{I}\left[\begin{array}{c}
\tilde{i}_{d} \\
\tilde{i}_{q}
\end{array}\right] \\
\text { and } K_{I}=\left[\begin{array}{cc}
K_{i d} & 0 \\
0 & K_{i q}
\end{array}\right]
\end{gathered}
$$

where gains of the integrator $K_{i d}$ and $K_{i q}$ are set to 500 and 200 respectively. The response time of the two current loops is set to

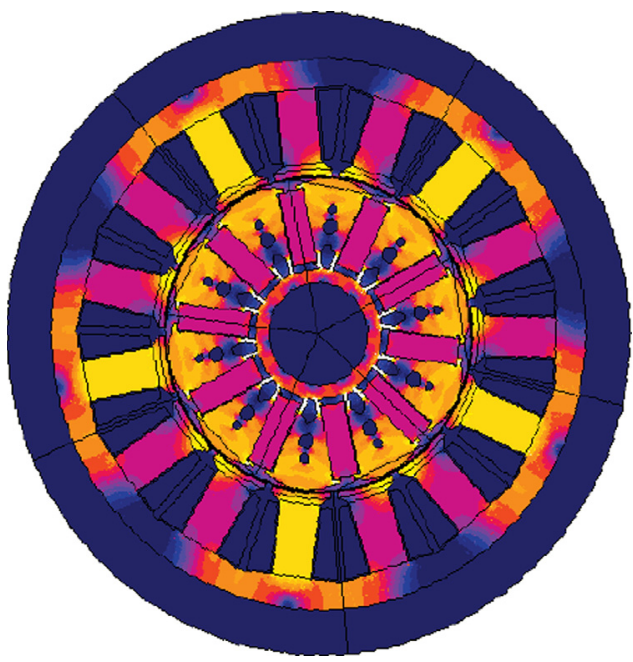

Fig. 2. Design of the interior PMSM.
$1 \mathrm{~ms}$. According to the experimental test bench, the load torque characteristic has been evaluated as shown in Fig. 4.

Figs. 4, 5 and 6 show the load torque $\tau_{l}$ applied to the motor, the mechanical speed, the quadrature current $i_{q}$ and the direct current $i_{d}$ which are control by the emulated and sample-data IDA-PBC respectively for a sampling time $T_{e}$ equal to $200 \mu \mathrm{s}$. The simulation shows that the controllers have the same behavior.

It is interesting to note that currents $i_{q e}$ and $i_{q k}$ are in advance compared to the desired currents while the measured speed does not reached the desired value. It means that the right part of Eq. (11) introduces a "feed-forward" term in the controller.

However, when the sampling period $T_{e}$ of the current-loop is increased, the ratio "closed-loop response time vs sampling time" is reduced and the stability properties of the emulated controller

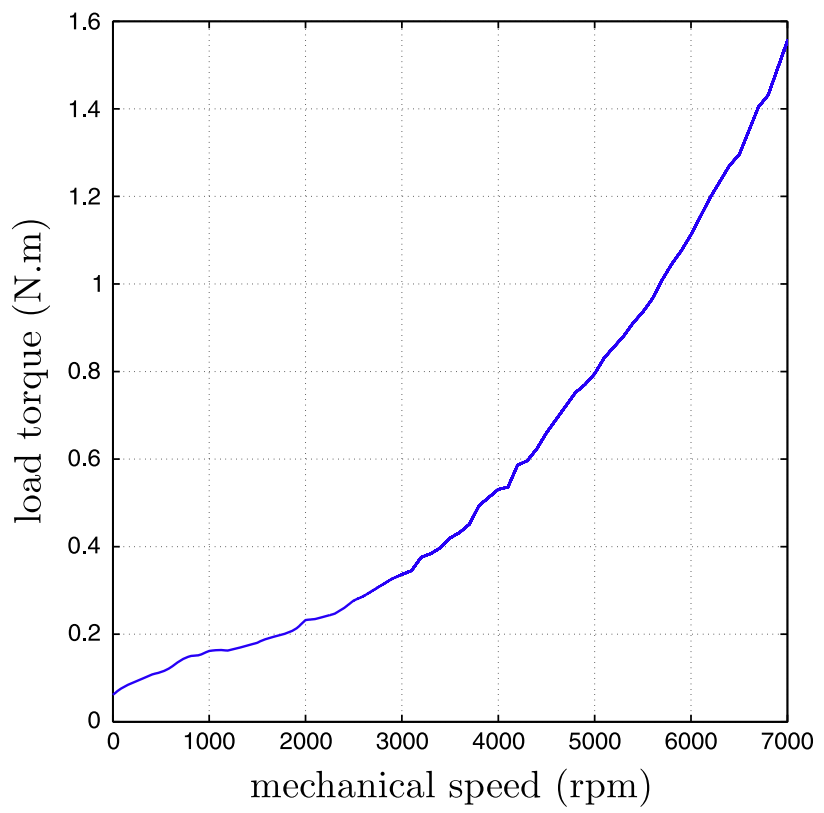

Fig. 4. Load torque characteristic. a

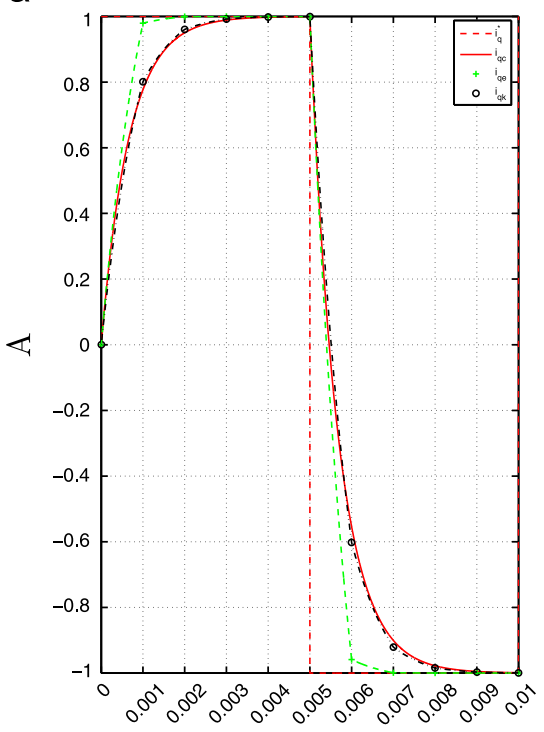

time $(\mathrm{s})$ b

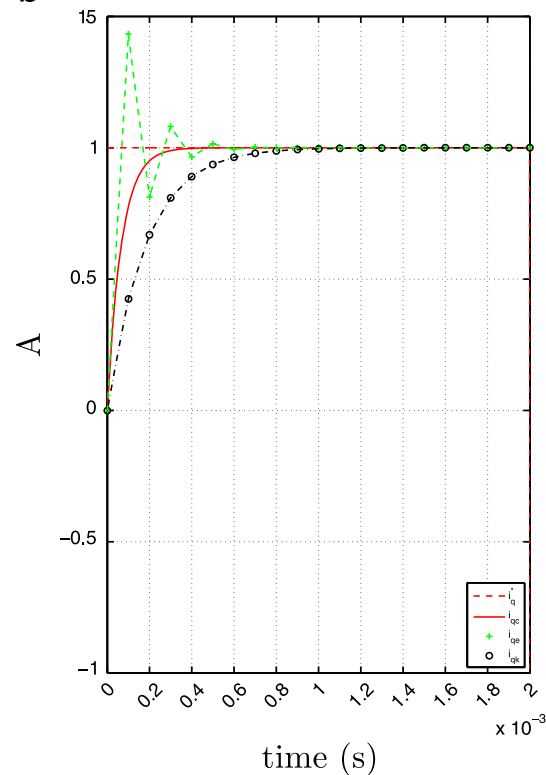

C

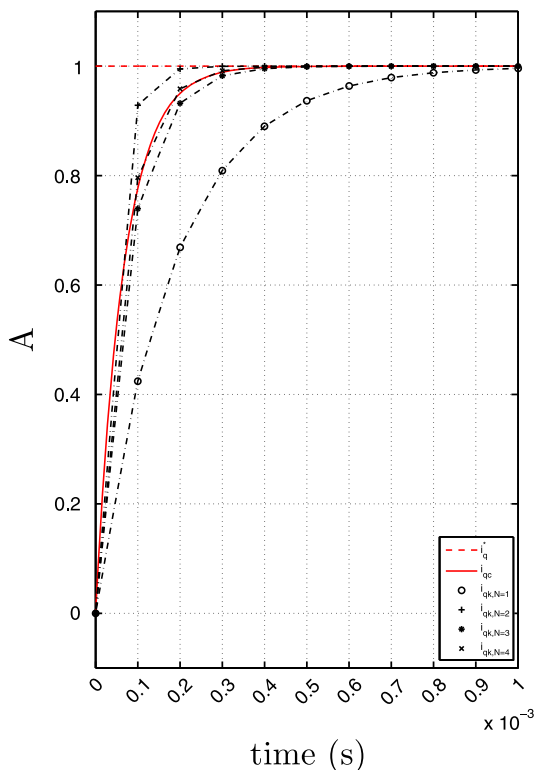

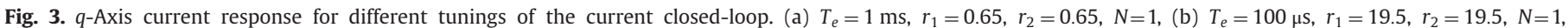
(c) $T_{e}=100 \mu \mathrm{s}, r_{1}=19.5, r_{2}=19.5, N=1$ to 4 . 
a

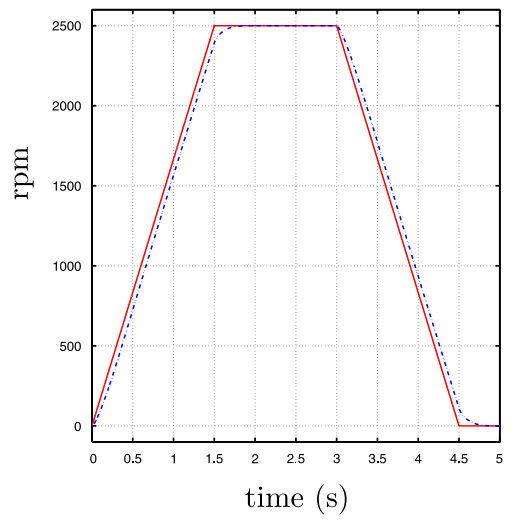

b

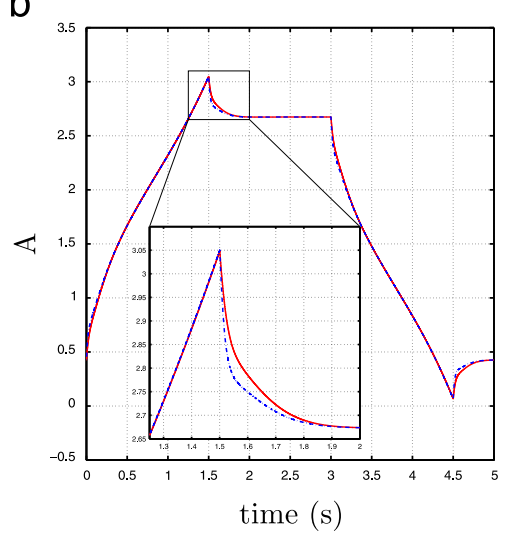

C

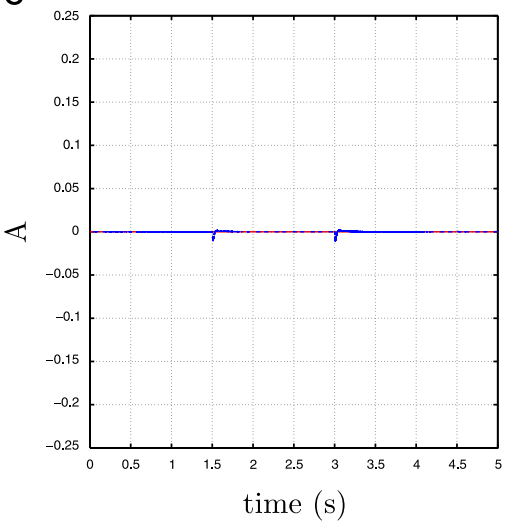

Fig. 5. Simulation of the emulated IDA-PBC with a sampled period equal to $200 \mu \mathrm{s}$. (a) $\Omega^{*}(-), \Omega\left(-\right.$ ), (b) $i_{q}^{*}(-), i_{q}\left(-\right.$ ), (c) $i_{d}^{*}(-), i_{d}(-$.).

a

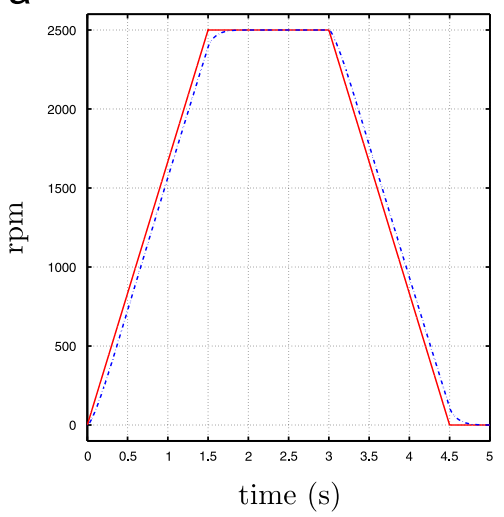

b

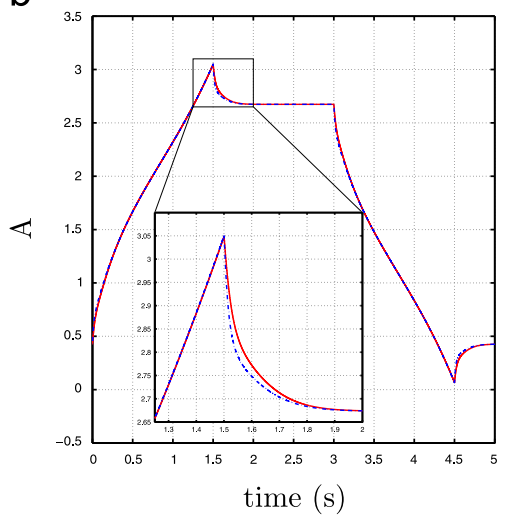

C

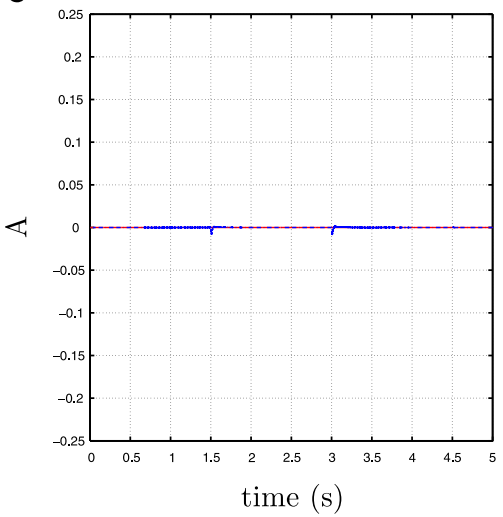

Fig. 6. Simulation of the sampled-data IDA-PBC with a sampled period equal to $200 \mu \mathrm{s}$. (a) $\Omega^{*}(-), \Omega\left(-\right.$ ), (b) $i_{q}^{*}(-), i_{q}\left(-\right.$.), (c) $i_{d}^{*}(-), i_{d}(-$.).

a

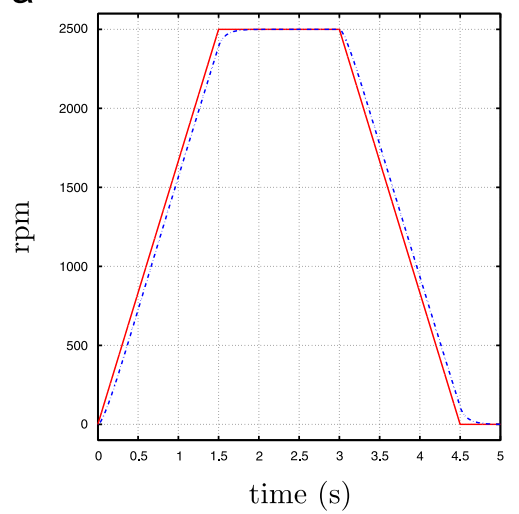

b

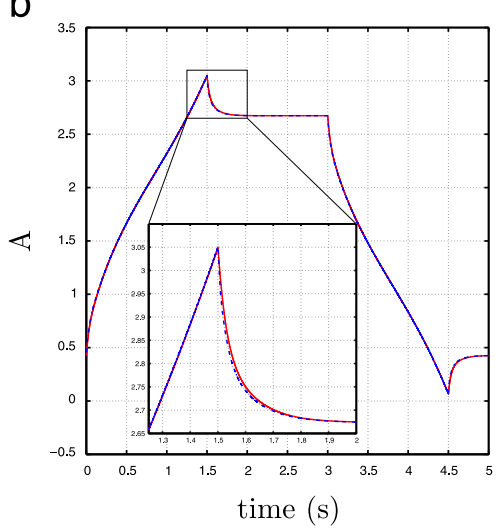

C

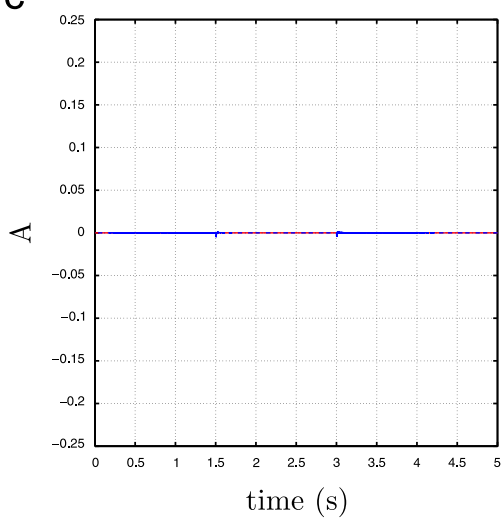

Fig. 7. Simulation of the sampled-data IDA-PBC with a sampled period equal to $500 \mu \mathrm{s}$. (a) $\Omega^{*}(-), \Omega\left(-\right.$.), (b) $i_{q}^{*}(-), i_{q}\left(-\right.$.), (c) $i_{d}^{*}(-), i_{d}(-$.).

are lost. In our configuration, it follows that the stability has been preserved for ratio greater than 4 .

As previously shown in Fig. 3, the sampled-data controller can retrieve the stability of the current-loop with additional terms in the controller equations. Fig. 7 shows the performance of these latter controllers for a sampling time $T_{e}$ equal to $500 \mu$ s, i.e. a ratio "closed-loop response time vs sampling time" equal to 2. While the emulated controller fails, the sampled-data controller keeps good performances. It confirms the effectiveness of this new controller in a sampled-data context.

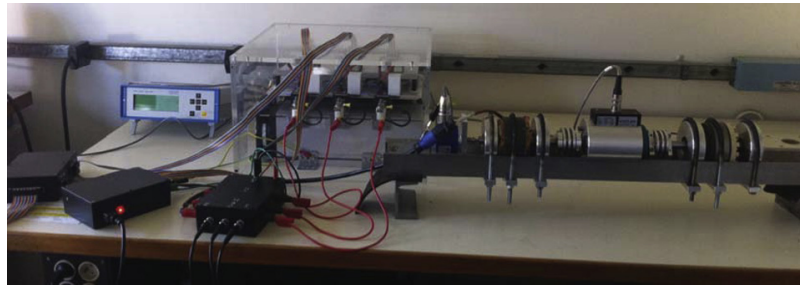

Fig. 8. Test bench. 
a

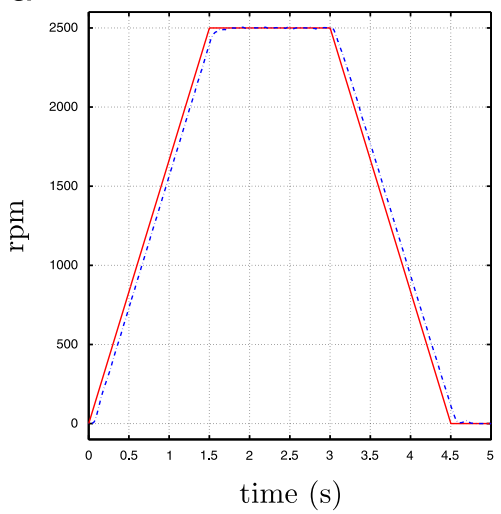

b

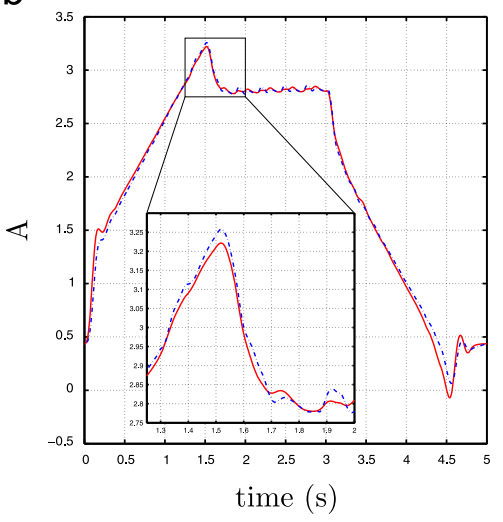

C

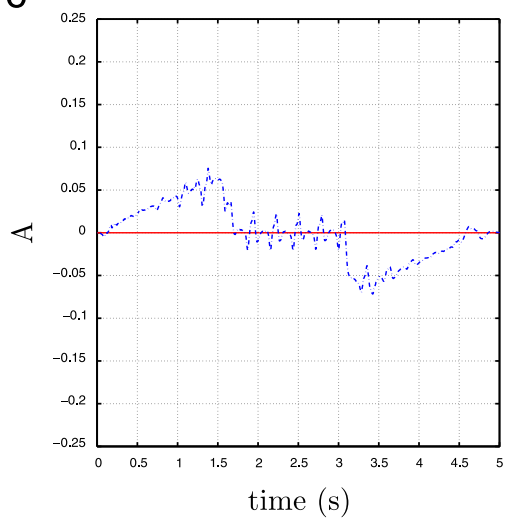

Fig. 9. Experimentation of the sampled-data IDA-PBC with a sampled period equal to $500 \mu \mathrm{s}$. (a) $\Omega^{*}(-), \Omega\left(-\right.$.), (b) $i_{q}^{*}(-), i_{q}\left(-\right.$.), (c) $i_{d}^{*}(-), i_{d}(-$.).

Table 1

Algorithm complexity.

\begin{tabular}{|c|c|c|c|c|}
\hline & \multicolumn{2}{|l|}{ Emulated controller } & \multicolumn{2}{|l|}{ Sample-data controller } \\
\hline & $\begin{array}{l}\text { Number of } \\
\text { additions and subtraction }\end{array}$ & $\begin{array}{l}\text { Number of } \\
\text { multiplications }\end{array}$ & $\begin{array}{l}\text { Number of } \\
\text { additions and subtraction }\end{array}$ & $\begin{array}{l}\text { Number of } \\
\text { multiplications }\end{array}$ \\
\hline Non-salient machine & 3 & 5 & 12 & 18 \\
\hline Salient machine & 4 & 6 & 18 & 29 \\
\hline
\end{tabular}

\subsection{Experimental test}

The PMSM is driven by a three-phase voltage source PWM inverter using an intelligent power module from ARCEL with IGBT modules at a switching frequency of $10 \mathrm{kHz}$ and a dead-time of $1.85 \mu$ s. The machine is mechanically coupled to an IPMSM (both machines have the same characteristics) and loaded by a rheostat (see Fig. 8). The currents flowing in the stator windings are measured with two Hall effect current sensors and a 3600 point pulse incremental encoder is used as a position sensor.

The experimental laboratory test bed control equipment is based on a DS1104 controller board from dSPACE GmbH. The development software operates under a Matlab/Simulink environment: real-time interface (RTI) which is the implementation software and ControlDesk which is the experimentation software in order to control and monitor in real-time the whole drive.

Fig. 9 shows the experimental results of the sampled-data controller for a sampling time $T_{e}$ equal to $500 \mu \mathrm{s}$. This test shows the advantages of this control in terms of stability at low sampling frequency. Moreover, robustness tests have been applied and show that the sampled-data controller still ensures good performances with detuning parameters.

\subsection{Discussion}

While sampled-data controller still ensures a good current control for ratio "closed-loop response time vs sampling time" lower than 4, with acceptable ripple, the emulated strategy degrades the control objectives. Moreover, while the sampling frequency is reduced, the shape of the current which is controlled by the sampled-data IDA-PBC remains more and more smooth (see Figs. $6 c$ and $7 c$ ). The simulation shows that current ripples begin to appear when the sampling period is greater than $250 \mu$ s with the emulated IDA-PBC.

Finally, the computational cost of this new controller is compared to the regular emulated IDA-PBC, as shown in Table 1. We can notice that the ratio "number of operations/sampling period"
Table 2

Machine parameters.

\begin{tabular}{ll}
\hline Rated output power & $P_{n}=6 \mathrm{~kW}$ \\
Rated torque & $C_{n}=5.5 \mathrm{~N} \mathrm{~m}$ \\
Rated speed & $N=6000 \mathrm{rpm}$ \\
Rated voltage & $V_{n}=350 \mathrm{~V}$ \\
Rated current & $I_{n}=22.5 \mathrm{~A}$ \\
Stator resistance & $R_{s}=0.165 \Omega$ \\
Stator inductance $d$-axis & $L_{d}=0.95 \mathrm{mH}$ \\
Stator inductance $q$-axis & $L_{q}=1 \mathrm{mH}$ \\
Rated flux & $\Phi=0.03 \mathrm{~Wb}$ \\
Number of pole pairs & $P=5$ \\
Inertia load & $J=6 \times 10^{-4} \mathrm{~kg} \mathrm{~m}{ }^{2}$ \\
Viscous coefficient & $f=0.0005 \mathrm{~N} \mathrm{~m} / \mathrm{s}$ \\
\hline
\end{tabular}

of the two controllers is lower for the sampled-data controller for the same system performances. Moreover, the use of higher sampling period with the new controller reduces the number of push/pop operations of the stack to save or restore the registers (computer science).

\section{Conclusion}

A direct sampled-data controller based on the IDA-PBC technique is developed for the current control of a PMSM. Such a controller is compared with the regular implementation, the so-called emulated strategy, which consists to implement the continuous-time controller through a zero order holder device. Simulation and experimental results show that the performances of the emulated control decrease while the sampling period increases. On the contrary, the sampleddata IDA-PBC ensures a good current control with the high sampling time. 


\section{References}

Akrad, A. Hilairet, M., Diallo, D., \& Ortega, R. (2007). Interconnection and damping assignment approach for reliable PM synchronous motor control. In IET colloquium on reliability in electromagnetic systems (pp. 1-6).

Baik, I., Kim, K., \& Young, M. J. (2002). Robust nonlinear speed control of PM synchronous motor using boundary layer integral sliding mode control technique. IEEE Transactions on Control Systems Technology, 8, 47-54.

Bose, B. (2002). Modern power electronics and AC drives. New Jersey: Prentice-Hall.

Buja, G., \& Kazmierkowski, M. (2004). Direct torque control of PWM inverter-fed ac motors-A survey. IEEE Transactions on Industrial Electronics, 51, 744-757.

Chelouah, A. K., Monaco, S., \& Normand-Cyrot, D. (1997). Digital nonlinear speed regulation of a synchronous motor. Automatika i Telemekhanika, 6, 143-158.

Delemontey, B., Iung, C., Jacquot, B., de Fornel, B., \& Bavard, J. (1995). Stability analysis and stabilisation of an induction motor drive with input filter. In European conference on power electronics and applications (EPE) (pp. 3211-3216)

Donaire, A., \& Junco, S. (2009). On the addition of integral action to port-controlled hamiltonian systems. Automatica, 45, 1910-1916.

Donaire, A., Perez, T., \& Teo, Y. (2012). Robust speed tracking control of synchronous motors using immersion and invariance. In The 7th IEEE conference on industrial electronics and applications (ICIEA) (pp. 1482-1487).

Gautier, A., Thomas, J., Poullain, S., Monaco, S., \& Normand-Cyrot, D. (2000) Optimisation discrétisation et observateurs - Commande des moteurs asynchrones 2 - Chapitre 3: Commande non linéaire en temps discret du moteur asynchrone. Hermes Science Publications (in French).

Georgiou, G., Chelouah, A., Monaco, S., \& Normand-Cyrot, D. (1992). Nonlinear multirate adaptive control of a synchronous motor. In Proceedings of the 31st IEEE conference on decision and control (Vol. 4, pp. 3523-3528). http://dx.doi. org/10.1109/CDC.1992.370999.

Giri, F. (Ed.). (2013). AC electric motors control: Advanced design techniques and applications. U.K: Wiley ISBN: 978-1-118-33152-1.

Hernandez-Guzman, V., \& Silva-Ortigoza, R. (2011). Pi control plus electric current loops for PM synchronous motors. IEEE Transactions on Control Systems Technology, 19, 868-873.

Khanchoul, M., \& Hilairet, M. (2011). Design and comparison of different RST controllers for PMSM control. In IEEE international conference on industria electronics (IECON)

Laghrouche, S., Plestan, F., \& Glumineau, A. (2004). A higher order sliding mode controller for a class of mimo nonlinear systems: Application to PM synchronous motor control. In American control conference (Vol. 3, pp. 2592-2597).

Li, S., \& Liu, Z. (2009). Adaptive speed control for permanent-magnet synchronous motor system with variations of load inertia. IEEE Transactions on Industrial Electronics, 56, 3050-3059.
Madani, K., Bonnassieux, Y., Monaco, S., \& Normand-Cyrot, D. (1997). Nonlinear digital control of a PMSM, invited paper. In International symposium on diagnostics for electrical machines, power electronics \& drives (SDEMPED).

Mariethoz, S., Domahidi, A., \& Morari, M. (2009). A model predictive control scheme with torque ripple mitigation for permanent magnet motors. In 35th annual conference of IEEE industrial electronics IECON (pp. 2943-2948).

Monaco, S., \& Normand-Cyrot, D. (1997). In: A. J. Fossard, \& D. Normand-Cyrot (Eds.), On nonlinear digital control - nonlinear systems - control 3 (pp. 127-155). London, U.K: Chapman \& Hall.

Monaco, S., Normand-Cyrot, D., \& Tiefensee, F. (2008). From passivity under sampling to a new discrete-time passivity concept. In Proceedings of the 47th IEEE CDC (pp. 3157-3162)

Monaco, S., Normand-Cyrot, D., \& Tiefensee, F. (2009). Nonlinear port controlled Hamiltonian systems under sampling. In Proceedings of the 48th IEEE CDC/CCC (pp. 1782-1787), Shanghai.

Monaco, S., Normand-Cyrot, D., \& Tiefensee, F. (2011). Sampled-data stabilization: A PBC approach. IEEE Transactions on Automatic Control, 56, 907-912.

Ortega, R., \& Garcia-Canseco, E. (2004). Interconnection and damping assignment passivity-based control: A survey. European Journal of Control, 10, 432-450.

Ortega, R., van der Schaft, A., Castanos, F., \& Astolfi, A. (2008). Control by interconnection and standard passivity-based control of port-Hamiltonian systems. IEEE Transactions on Automatic Control, 53, 2527-2542.

Petrovic, V., Ortega, R., \& Stankovic, A. (2001). Interconnection and damping assignment approach to control of PM synchronous motors. IEEE Transactions on Control Systems Technology, 9, 811-819.

Stramigioli, S., Secchi, C., der Schaft, A., \& Fantuzzi, C. (2005). Sampled data systems passivity and discrete port-Hamiltonian systems. IEEE Transactions on Robotics, 21, 574-587.

Tiefensee, F., Hilairet, M., Normand-Cyrot, D., \& Béthoux, O. (2010). Sampled-data energetic management of a fuel cell/supercapacitor system. In IEEE vehicle power and propulsion conference (VPPC).

Tiefensee, F., Monaco, S., \& Normand-Cyrot, D. (2009). Lyapunov design under sampling for a synchronous machine. In ECC'09 (pp. 2775-2780).

Tiefensee, F., Monaco, S., \& Normand-Cyrot, D. (2010). IDA-PBC under sampling for port-controlled Hamiltonian systems. In American control conference (ACC) (pp. 1811-1816).

Wang, Y., Zhu, J., \& Guo, Y. (2007). A survey of direct torque control schemes for permanent magnet synchronous motor drives. In Power engineering conference AUPEC (pp. 1-5).

Zhou, J., \& Wang, Y. (2002). Adaptive backstepping speed controller design for a permanent magnet synchronous motor. IEE Proceedings Electric Power Applications, 149, 165-172. 